\title{
The assessment of diagnostic medical images using 10-bit grayscale - fact or myth?
}

\author{
Robert Chrzan ${ }^{A, B, C, D, E, E, G,}$, Andrzej Urbanik ${ }^{A, E}$ \\ Department of Radiology, Jagiellonian University Medical College, Cracow, Poland
}

\section{Abstract}

Purpose: The aim of the study was to find tests for verification of 10-bit grayscale support for radiological workstation hardware/operating system and for DICOM viewer. Also, we wanted to perform the tests on available workstations.

Material and methods: The following tests were selected to verify 10-bit grayscale support: workstation hardware and operating system tests using DirectX SDK 10BitScanout10.exe and NEC 10bitdemo.exe programs, DICOM viewer tests using TG18-MP and TG18-QC patterns. The tests were performed on 14 radiological workstations in a local department of radiology and on 4 radiological workstations during the technical exhibition at the ECR (European Congress of Radiology) in 2017.

Results: Only 3 out of 14 local workstations passed the hardware and operating system 10-bit grayscale support test. Only one workstation passed the DICOM viewer 10-bit grayscale support test.

Conclusions: Hardware/operating system and DICOM viewer 10-bit grayscale support should be tested on every radiological workstation even if compatibility is stated by the manufacturer. Existing medical diagnostic display quality requirements should be adjusted so that 10-bit support for DICOM viewers is only a desirable option.

Key words: data display, diagnostic imaging, quality control.

\section{Introduction}

Proper display quality is crucial for medical diagnostic imaging assessment. Technical requirements for medical display systems were specified many years ago. Since that time legal regulations or professional guidelines have been introduced in many countries to ensure regular quality assessments [1-10].

In Poland, the quality requirements for medical monitors used to display images from $\mathrm{X}$-ray-based modalities are defined in Attachment no. 1 'Wymagania dotyczące opisu i przeglądu obrazów rejestrowanych w postaci cyfrowej' for the Regulation 'Rozporządzenie w sprawie warunków bezpiecznego stosowania promieniowania jonizującego dla wszystkich rodzajów ekspozycji medycznej' - Dz. U. z 2013 poz. 1015 [1], Dz. U. z 2015 poz. 2040 [2], Dz.U. z 2017 poz. 884 [3].
During periodical medical monitor quality tests, various predefined parameters are checked, especially maximal luminance, contrast, and DICOM GSDF (Grayscale Standard Display Function) curve conformance.

According to the Attachment no. 1 mentioned above, every element of image transmission and presentation on radiological diagnostic workstation (including graphics card) must provide the ability to pass 1024 levels of gray (10 bits).

The above statement suggests that DICOM viewer that is an inherent part of presentation system should support a 10-bit grayscale for all X-ray-dependent imaging techniques in the same way as workstation hardware and operating systems do.

Conventional display devices use 8-bits per each of the red, green, and blue color channels, which equals to 24-bits per every pixel of displayed image. In grayscale images, all the 3 color channels have the same value, thus

Correspondence address:

Robert Chrzan, Department of Radiology, Jagiellonian University Medical College, Kopernika 19 St., $31-501$ Cracow, Poland, e-mail: rchrzan@mp.pl

Authors' contribution:

A Study design · B Data collection · C Statistical analysis · D Data interpretation · E Manuscript preparation · F Literature search · G Funds collection 
it is possible to get only an 8-bit grayscale (256 levels) with conventional devices [11-13].

10-bit displays use 10 bits to represent each of the 3 color channels and thus every pixel is represented with 30 bits instead of 24 bits as in conventional displays. Finally, 10-bit displays can generate more than a billion shades of colors or a 10-bit grayscale (1024 levels) [11-13].

Even if such a 10-bit pixel format is implemented by hardware (graphics card chip), the Display Port output connection to the monitor must be used to utilize this feature by the operating system.

For medical displays working with only grayscale levels, some vendors may also use another technique called 'Pixel Packing' [12] whereby the 10-bit or even 12-bit grayscale data are transmitted from the graphics card to a high grayscale density display using a DVI (Digital Visual Interface) cable. Instead of the standard three 8-bit color components per pixel, pixel packing allows two 10- or even 12-bit pixels to be transmitted, providing higher spatial resolution and grayscale pixel depth as compared to 8-bit systems. In recent drivers, pixel packing is done by drivers transparent to the application when 10-bit per component pixel formats are used. This greatly simplifies programming but works only with selected graphics cards or monitors.

Notably, using hardware and operating system supporting a 10-bit grayscale is not enough to display DICOM images in simultaneous 1024 levels of gray. To achieve this goal, the DICOM viewer software should be aware of 10-bit grayscale hardware and operating system support to use different program routines for displaying the images as well as not 8-bit but 10-bit internal Lookup Tables (LUTS).

The aim of the study was to find tests for verification of 10-bit grayscale support for workstation hardware/operating system and for DICOM viewer. Also, we wanted to perform the tests on available workstations.

\section{Material and methods}

After getting acquainted with the available internet resources concerning the subject, including hardware/operating system implementation [11-13] and displayed image features [5-10], the following tests were selected to verify 10-bit grayscale support:
1. Workstation hardware and operating system 30-bit color - 10-bit grayscale support test.

The tested monitor must be connected via the Display Port. Only for older solutions of some manufacturers ('Pixel Packing'), it is acceptable to connect the monitor using a DVI Dual Link, but the support for 10-bit grayscale using such connection must be explicitly confirmed in the monitor and graphics card specifications.

10-bit grayscale mode must be enabled in the graphics card driver settings.

In multi-monitor configurations using both diagnostic 30 -bit color and reporting 24-bit color monitors, before running the test programs, it is suggested to set the tested diagnostic monitor as the main display in the screen settings. Default setting of a reporting monitor as the main display may result in incorrect operation of test programs on diagnostic monitors.

The test windows must be displayed entirely in the tested monitor area only. If a part of the window is displayed in the 24-bit color monitor area, then the rest of the window in the 30 -bit color monitor area will function only as in the 24-bit color monitor area.

Test programs:

a) 10BitScanout10.exe (Figure 1).

The program is included in the DirectX Software Development Kit - available at:

https://www.microsoft.com/en-us/download/details.aspx?id=6812 the program is installed in:

C: \Program Files \Microsoft DirectX SDK (June 2010) \ Samples $\backslash C++\backslash$ Direct3D10 $\backslash$ Bin $\backslash x 86 \backslash 10 B i t S c a n o u t 10 . e x e$ To use the program on another computer, one needs to copy the above file and additionally the shader file:

C: \Program Files \Microsoft DirectX SDK (June 2010) \

Samples $\backslash \mathrm{C}++\mid$ Direct3D10 $\backslash 10 \mathrm{BitScanout10 \backslash}$

10BitScanout10.fx

to an arbitrary selected directory on the target computer, and upgrade DirectX End-User Runtime:

https://www.microsoft.com/en-us/download/details.aspx?id=8109 without the need to install the huge full-featured DirectX Software Development Kit.

DirectX 10 must be supported by the graphics card to run the program.

When one starts the program, Alt + Enter switches to full screen mode, while F8/F10 switches between 8- and 10-bit grayscale.

Table 1. Summary of 10-bit grayscale support test results

\begin{tabular}{|c|c|c|c|}
\hline \multicolumn{4}{|c|}{18 radiological workstations tested } \\
\hline \multicolumn{2}{|c|}{ Hardware and operating system 10-bit grayscale support } & \multicolumn{2}{|c|}{ DICOM viewer 10-bit grayscale support } \\
\hline No & Yes & No & Yes \\
\hline 11 & 7 & 17 & 1 \\
\hline \multicolumn{4}{|l|}{ 9. № Display Port output in graphics card } \\
\hline \multicolumn{4}{|l|}{ 1. No Display Port cable used } \\
\hline 1. Graphics card driver option disabled & & & \\
\hline
\end{tabular}




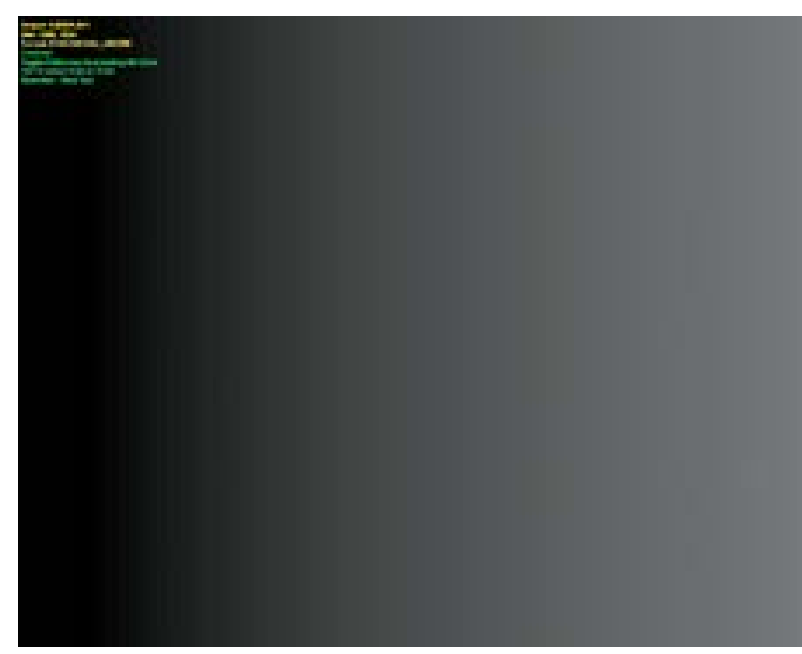

Figure 1. 10BitScanout10.exe test program

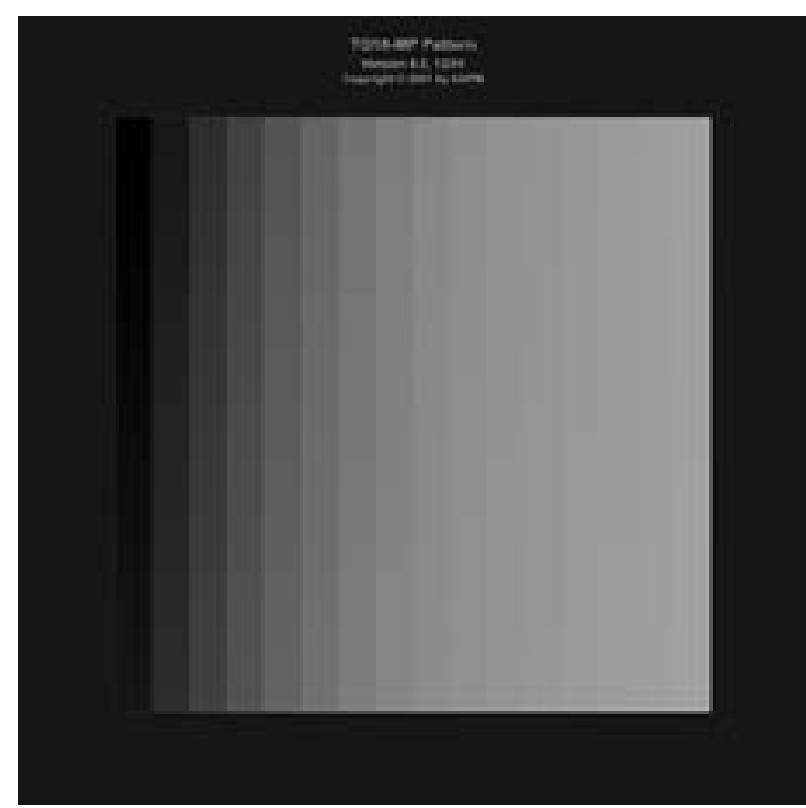

Figure 3. TG18-MP test pattern

If one switches from F8 to F10 and one does not see vertical bars on the test image consisting of gray levels from black on the left to white on the right, then the tested workstation hardware and operating system support 30bit color mode - 10-bit grayscale.

b) NEC 10bitdemo.exe (Figure 2).

This is a dedicated program for NEC monitors, but it should also work with most monitors from other manufacturers. After downloading the program from NEC at:

http://www.necdisplay.com/documents/Software/NEC_10_bit_video_Windows_demo.zip one unpacks and runs the program.

If after launching the program one gets two windows with rotating geometric figures, and no bars limiting color tonal gradients are visible on the window labeled as 10-bit, contrary to the window labeled as 8-bit, the tested workstation hardware and the operating system support 30-bit color mode - 10-bit grayscale.

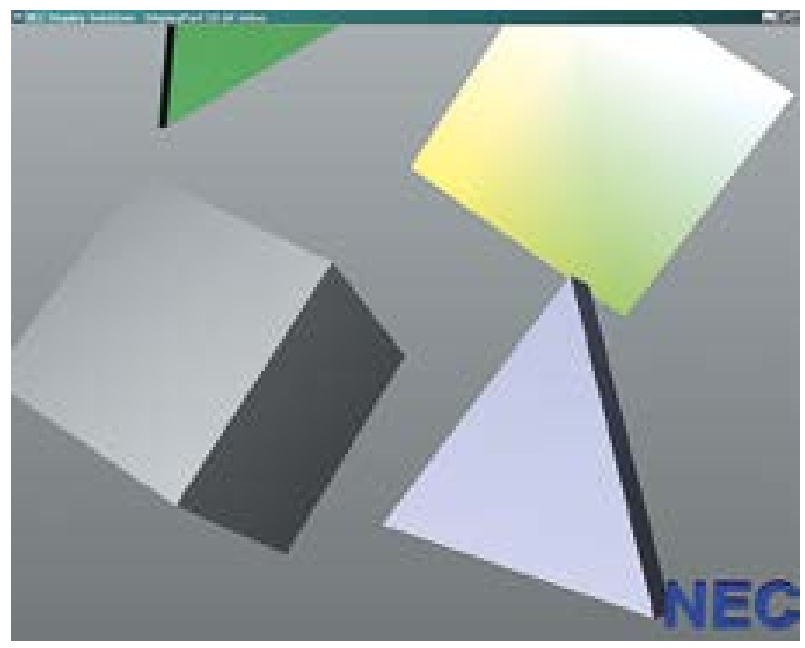

Figure 2. 10bitdemo.exe test program

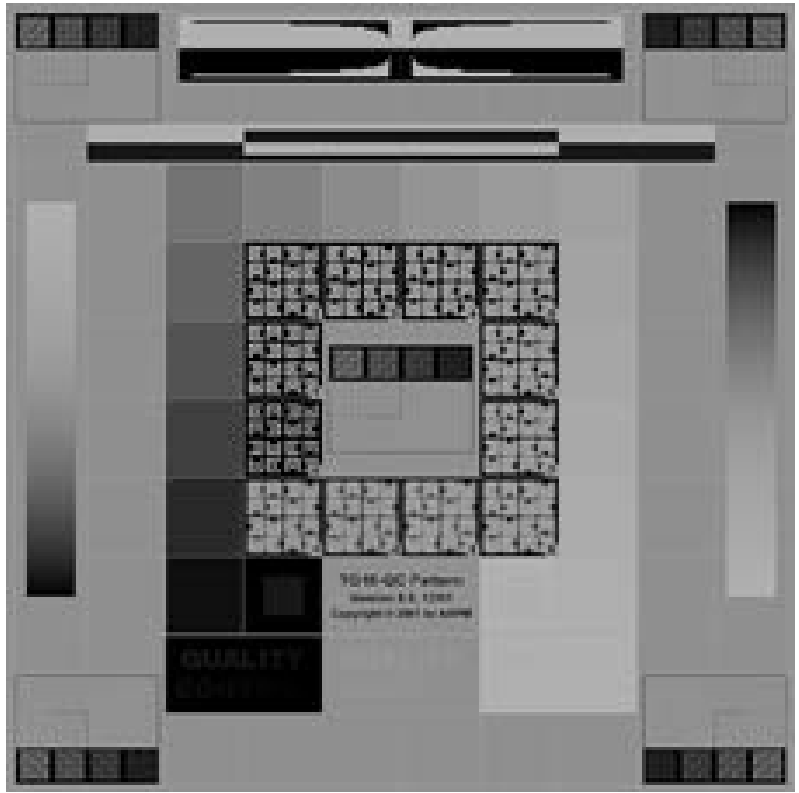

Figure 4. TG18-QC test pattern

2. DICOM viewer 10-bit grayscale support test.

After a positive result of 30-bit color - 10-bit grayscale support test for workstation hardware and operating system, one can perform DICOM viewer 10-bit grayscale support test.

Test patterns:

a) TG18-MP (Figure 3).

After downloading the file from the website of the American Association of Physicists in Medicine (AAPM) Task Group 18 ( $1 \mathrm{k}$ luminance patterns), available at http://deckard.mc.duke.edu/ samei/tg18_files/lumin-1k-dcm.zip one unpacks it and using the tested viewer opens the file TG18-MP-1k-01.dcm

Once opened, one does not change the contrast/ brightness, but can enlarge the image. If horizontal borders are visible on vertical grayscale stripes at distances as wider markers, the grayscale is only 8 -bit (16 strips $\times 16$ parts $=256$ levels). 
If these borders are not visible or are visible at distances as narrower markers, the grayscale scale is 10-bit (16 strips $\times 64$ parts $=1024$ levels $)$.

b) TG18-QC (Figure 4).

After downloading the file from the website of the American Association of Physicists in Medicine (AAPM) Task Group 18 (2k TG18-QC pattern), available at http://deckard.mc.duke.edu/ samei/tg18_files/TG18-QC-2k-dcm.zip one unpacks it and using the tested viewer opens the file TG18-QC-2k-01.dcm

Once opened one does not change the contrast/brightness, but can enlarge the image.

One can enlarge one of the vertical stripes on the sides of the image; they consist of 1024 horizontal bars changing the grayscale level using every $4^{\text {th }}$ value from 0 to 4096 .

If in the image every 4 successive horizontal bars have the same brightness - they are merging, then the grayscale is only 8 bit. If every single successive horizontal bar has a slightly different brightness, then the grayscale is $10 \mathrm{bit}$.

The above-described tests were performed on 14 radiological workstations in the Department of Radiology, University Hospital, Cracow, Poland; the stations included 9 CT assessment stations, 4 digital radiography assessment stations, and 1 digital mammography assessment station.

Additionally, the tests were scheduled to be performed on the radiological workstations of the main manufacturers during the technical exhibition at the ECR (European Congress of Radiology) 2017.

Because of legal/public relations aspects, we decided not to disclose herein the names of vendors whose hardware or software did not pass the tests. Notably, hardware manufacturers cannot be responsible for improper use of cable connection or software (DICOM viewer) that do not support 10-bit grayscale.

\section{Results}

Tests of the workstations in the Department of Radiology, University Hospital in Cracow:

According to manufacturers' specifications, all the tested monitors supported displaying at least at a 10-bit grayscale. However, most of the workstations tested did not pass the hardware and operating system 10-bit grayscale support test:

- 8 out of 9 CT assessment stations had diagnostic monitors supporting 10-bit grayscale only when connected via Display Port, while the monitors were connected via DVI Single Link instead of Dual Link, and the graphics card had no Display Port output,

- 1 out of 4 digital radiography assessment stations had diagnostic monitors supporting 10-bit grayscale only when connected via Display Port, while the monitors were connected via DVI Dual Link, although the graphics card had Display Port output,
- 1 out of 4 digital radiography assessment stations supported 10-bit grayscale only after the user turned on the appropriate graphics card driver option, disabled by default, - 1 digital mammography assessment station had diagnostic monitors supporting 10-bit grayscale only when connected via Display Port, while the monitors were connected via DVI Dual Link and the graphics card had no Display Port output.

For 2 digital radiography assessment stations, 10-bit grayscale support was confirmed using DVI Dual Link, because monitors and dedicated graphics cards from the same manufacturer, using their own hardware solution ('Pixel Packing'), did not require Display Port.

However, none of the tested stations with hardware and operating system confirmed to support 10-bit grayscale passed the DICOM viewer 10-bit grayscale test.

Tests of the workstations and DICOM viewers at the ECR 2017 technical exhibition:

Out of the 8 manufacturers approached, only in 4 cases permission for tests was obtained. Out of the 4 tested workstations, full 10-bit grayscale support, both by hardware/ operating system and DICOM viewer, was confirmed only for the Sectra workstation.

A short summary of 10-bit grayscale support test results is presented in Table 1.

\section{Discussion}

According to the Polish regulations, every element of image transmission and presentation on the radiological diagnostic workstation (including graphics card) must provide the ability to pass 1024 levels of gray (10 bits) [1].

The above statement also suggests that the DICOM viewer, as an inherent part of the presentation system, should support 10-bit grayscale, not only for mammography or digital radiography but for all imaging techniques using X-rays.

However, full implementation of 10-bit grayscale is rare in practice. Most users are unaware of this fact, and assume that purchasing professional medical monitors that support at least a 10-bit grayscale is enough to meet the above requirements. Moreover, periodic medical monitors quality tests performed in major medical centers do not include 10-bit grayscale assessment. During such tests, declared support of at least 10-bit grayscale for monitors is considered as the basis for achieving the desired 256 grayscale levels distribution during calibration according to the DICOM GSDF (Grayscale Standard Display Function) curve.

The American Association of Physicists in Medicine (AAPM) Task Group 18 created a widely used set of testing procedures for quality assessment of medical imaging systems, including the use of standard test images $[8,9]$. In the original description of the grayscale depth using the TG18-MP pattern, it is only stated that the calibrated display needs at least an 8-bit grayscale. However, it should 
be noted that in the year of this publication (2005), tube monitors and early generations of liquid crystal displays were widely used in radiology, and thus meeting the requirement of at least an 8-bit grayscale was quite a challenge.

The European Reference Organization for Quality Assisted Breast Screening and Diagnostic Services (EUREF) issued recommendations for mammography quality assessment [5], that are also implemented in the Polish regulations (Attachment no. 1) [1].

The above-mentioned recommendations do not include an absolute requirement to support a 10-bit grayscale by all components of the mammographic image display system.

Thus, the question arises if full implementation of the 10-bit grayscale is really needed in radiology?

Tabar [14] found a significantly improved accuracy of screening mammography using 10-bit grayscale mammography workstation (ROC Az 0.8306) compared to an 8-bit grayscale (ROC Az 0.7912). Thus, full 10-bit grayscale support is not only a sophisticated technological innovation, but it may provide practical benefits.

Kimpe [15] demonstrated, by using the Barten model, that the human observer can perceive no more than around 900 shades of gray, so display systems that are able to show 1024 simultaneous shades of gray (10 bits) are sufficient for medical imaging. However, the display needs to be calibrated to DICOM GSDF, selecting 1024 levels from a wider palette of available gray shades. That is why diagnostic monitors should ensure an internal 11-bit or even 12-bit grayscale.
Manufacturers of graphics chips introduced 30-bit color support a few years ago to improve display quality in professional graphic and medical imaging applications.

However, wide implementation of this feature in diagnostic imaging is still limited.

Moreover, existing legal regulations and quality requirements may not well correspond to real-life situations because of demanding solutions which are not easily available on the market.

This may even lead to legal problems if the issue of medical imaging quality requirements arises.

Thus, it is suggested to adjust the existing quality requirements.

The 10-bit grayscale support must be required for diagnostic monitors to achieve DICOM GSDF calibration.

However, 10-bit support for DICOM viewer should still be treated only as a desirable option.

\section{Conclusions}

Hardware/operating system and DICOM viewer 10-bit grayscale support should be tested on every radiological workstation even in the case of manufacturer's statement of compatibility.

Existing medical diagnostic display quality requirements should be adjusted so that 10-bit support for DICOM viewer is treated only as a desirable option.

\section{Conflict of interest}

The authors report no conflict of interest.

\section{References}

1. Minister Zdrowia. Obwieszczenie Ministra Zdrowia z dnia 26 kwietnia 2013 r. w sprawie ogłoszenia jednolitego tekstu rozporządzenia Ministra Zdrowia w sprawie warunków bezpiecznego stosowania promieniowania jonizującego dla wszystkich rodzajów ekspozycji medycznej. Dz.U. z 2013 poz. 1015. Available from:

http://dziennikustaw.gov.pl/DU/2013/1015/1 [in Polish].

2. Minister Zdrowia. Rozporządzenie zmieniające rozporządzenie w sprawie warunków bezpiecznego stosowania promieniowania jonizującego dla wszystkich rodzajów ekspozycji medycznej. Dz.U. z 2015 poz. 2040. Available from:

http://dziennikustaw.gov.pl/DU/2015/2040/1 [in Polish].

3. Minister Zdrowia. Obwieszczenie Ministra Zdrowia z dnia 3 kwietnia 2017 r. w sprawie ogłoszenia jednolitego tekstu rozporządzenia Ministra Zdrowia w sprawie warunków bezpiecznego stosowania promieniowania jonizującego dla wszystkich rodzajów ekspozycji medycznej. Dz.U. z 2017 poz. 884. Available from:

http://dziennikustaw.gov.pl/DU/2017/884/1 [in Polish].

4. Sekcja Inżynierii Klinicznej PLTR. Wymagania dotyczące stanowiska do interpretacji (stanowiska opisowego) dla radiologii cyfrowej. 2010. Available from:

http://los.net.pl/download.php?id=55 [in Polish].
5. EUREF. European protocol for the quality control of the physical and technical aspects of mammography screening. In: European guidelines for quality assurance in breast cancer screening and diagnosis Fourth edition. 2006. Available from:

http://www.euref.org/downloads?download=26:physico-technical-protocol

6. DIN Deutsches Institut für Normung. DIN 6868-157 Image quality assurance in diagnostic X-ray departments - Part 157: X-ray ordinance acceptance and constancy test of image display systems in their environment. Available from:

http://www.din.de/en/getting-involved/standards-committees/nar/standards/wdc-beuth:din21:216064441

7. The Institute of Physics and Engineering in Medicine. Report 91 Recommended Standards For The Routine Performance Testing of Diagnostic X-Ray Imaging Systems. Available from:

https://www.ipem.ac.uk/ScientificJournalsPublications/IPEMReportSeries/AvailablePublications.aspx

8. American Association of Physicists in Medicine (AAPM) Task Group 18. Assessment of display performance for medical imaging systems. 2005. Available from:

http://www.aapm.org/pubs/reports/or_03.pdf

9. Samei E, Badano A, Chakraborty D, et al. Assessment of display performance for medical imaging systems: Executive summary of AAPM TG18 report. Med Phys 2005; 32: 1205-1225. 
10. Japan Industries Association of Radiological Systems (JIRA). JESRA-X-0093 Quality Assurance (QA) Guideline for Medical Imaging Display Systems. Available from:

http://www.jira-net.or.jp/e/information/file2/JESRA_X-0093_A-2010_e.pdf

11. nVidia. 30-Bit Color Technology for NVIDIA ${ }^{\circ}$ Quadro $^{\circ} .2009$. Available from:

https://www.nvidia.com/docs/IO/40049/TB-04701-001_v02_new.pdf

12. nVidia. 10 and 12-bit grayscale technology. 2013. Available from: https://www.nvidia.com/content/quadro_fx_product_literature/TB-04631-001_v05.pdf

13. Advanced Micro Devices. AMD’s 10-bit Video Output Technology. 2008. Available from: https://www.amd.com/Documents/10-Bit.pdf

14. Tabár LK, Niño AS, Schreiber E, et al. Three digital mammography display configurations: Observer performance in a pilot ROC Study. In: Martí J, Oliver A, Freixenet J, Martí R (eds.). Digital mammography. IWDM 2010. Lecture Notes in Computer Science, vol. 6136. Springer, Berlin, Heidelberg.

15. Kimpe T, Tuytschaever $T$. Increasing the number of gray shades in medical display systems - how much is enough? J Digit Imaging 2007; 20: 422-432. 